\title{
A.JO'ГE
}

African Journal of Teacher Education

ISSN 1916-7822. A Journal of Spread Corporation

$\begin{array}{llll}\text { Vol. } 7 & \text { No. } 1 & 2018 & \text { pp. 36-52 }\end{array}$

\section{Science Curiosity as a Correlate of Academic Performance in Mathematics Education: Insights from Nigerian Higher Education}

\author{
Benjamin Ogbole Abakpa, \\ Joshua Abah Abah, and Abel Okoh Agbo-Egwu \\ Department of Science Education, \\ University of Agriculture, Makurdi, Nigeria.
}

\begin{abstract}
This study investigated the relationship between the science curiosity levels of undergraduate of mathematics education in a Nigerian higher educational institution and their academic grade point averages. The study employed a correlational survey research design on a random sample of 104 mathematics education students. The Science Curiosity Scale - Comparative Self Report was adapted to measure the students' distinctive appetite for consuming science-related media for personal edification. The correlational analysis of science curiosity scores and the students CGPA indicated a weak negative relationship $(r=-0.049, \mathrm{p}=0.621)$, suggesting an interplay of other important factors in the relationship between academic performance and science curiosity. Based on the findings of this study, it was recommended that key stakeholders of mathematics education consider curiosity as a complex ability related to several functions of the mind and that it enhances systematic commitment on the part of the learner, providing enormous foundational benefits that could be reaped in the process of educating students.
\end{abstract}

Keywords: Science curiosity, Academic performance, Nigerian higher education, Mathematics education

\section{Introduction}

Higher education in Nigeria is that stage in the education of the child at which the child becomes a stakeholder in his/her own learning experience. It is at the entry point to colleges of education, polytechnics and universities that students truly feel free from the influence and control of parents, perceived impositions by school teachers, the daily drab of the school 
uniforms and every form of corporal punishment. But with this liberty comes the responsibility and the need to blend lifestyle with learning and moderate all other factors towards a befitting academic performance.

Academic achievement represents performance outcomes that indicate the extent to which a person has accomplished specific goals in instructional environments such as school, college and university (Steinmayr, Meibner, Weidinger \& Wirthwein, 2015). Williams (n.d.) maintains that academic performance is reflected not only in a person's grades at school but also manifested in the individual's intelligence, participation in extracurricular activities, initiative in leadership and sustainable skills. Evidently, academic performance entails the overall well-being of an individual with respect to prescribed tasks. These views of academic performance suggest a wide range of factors, qualities and indicators, to be responsible.

Williams (n.d.) argues that the ability to master diverse set of skills illustrates intelligence, curiosity and persistence, qualities attractive to universities and employers. Von Stumm, Hell and Chamorro-Premuzic (2011) reported that much psychological research has focused on identifying predictors of academic performance, with intelligence and effort emerging as core determinants. However, in tandem with Williams (n.d.), the work of Von Stumm et al. (2011) clarified that typical intellectual engagement as a marker of intellectual curiosity is a direct, correlated predictor of academic performance.

Basically, curiosity is a passion for learning. Borowske (2005) affirms that curiosity is associated with scientific discovery, idle gossip, exploration, puzzles and even mysteries. Curiosity is widely valued as a desirable attribute of a fully developed person and is commonly depicted as an early feature of young children's orientation towards the world (Jirout \& Klahr, 2012). Aside being a principal component of motivation in learning, curiosity has been connected to memory enhancement in older adults (McGillivray, Murayama \& Castel, 2015).

Despite early setbacks and disagreements in establishing a firm footing for curiosity as a psychological construct, the fact of its indispensability is undeniable. It is easy to see curiosity at play in the early life of children but as they grow older this tendency to try out tempting impulses becomes lumped together with other range of easily identifiable and measurable traits such as attitude, interest, motivation and other drives. In recent times, accumulating researches on curiosity are beginning to pay off as scholars could now sift through the existential psychological soup to single out curiosity as distinctive measure. One of these ground-breaking 
efforts is attributable to Kahan, Landrum, Carpenter, Helft and Jamieson (2017), who viewed science curiosity as important individual difference in cognitive style that interacts distinctively with the way people process information.

Considering the current era of rapid change occasioned by technological innovations, the onus is on the student, particularly at the higher education level, to drive more personalized learning. As with other areas of education, science and mathematics have suffered from rapidly-changing political expectations and reforms (The Royal Society, 2010). The mathematics education student, specifically, may not entirely find himself in a cordial and supportive learning environment, and may have to look inward for ways of attaining enviable academic performance. In the midst of a thousand and one reasons to derail, intrinsic motivation cultivated via sustained science curiosity may be a beacon of hope for the mathematics education student in Nigeria.

In a bid to redirect thought patterns from very obvious causes and effects in mathematics education at Nigerian higher educational institutions, this study was designed to focus on curiosity, a latent human trait known to bridge barriers to success. How have mathematics education students in Nigerian universities been able to stir and manage their general curiosity in the course of their academic programmes? More importantly, what does their academic performance say about their level of science curiosity? How significant is this relationship, if it exists? And if the relationship exists, does it vary according to gender? These concerns form the major thrust of this investigation into science curiosity as a correlate of academic performance in mathematics education in Nigeria.

\section{Perspectives of Literature on Curiosity}

The journey to understand the nature of curiosity is a long and contemplative one. This is because curiosity overlaps with other psychological constructs such as behavioural activation system, positive effect, and sensation seeking. In presenting theory and research that distinguish curiosity from related constructs, Kashdan, Rose and Fincham (2004) defined curiosity as a positive emotional-motivational system associated with the recognition, pursuit and self-regulation of novel and challenging opportunities.

Most studies of curiosity consider four main theories about its nature. The first is the drive theory propounded by early curiosity scholar Daniel Berlyne, between 1954 and 1978. This perspective considers curiosity as biological in nature, and existing as a human drive, 
much like hunger or thirst, which is satisfied by the acquisition of knowledge (Rowson, Young, Spencer, Lindley \& Gecius, 2012). Thus, curiosity is seen as a basic instinct, an innate mechanism that enabled intelligent species to learn about and master new things in their environments, promoting survival, use of tools and ultimately technological advances (Arnone, Small, Chauncy \& McKenna, 2011). Curiosity prompts proactive, intentional behaviours in response to stimuli and activity with properties such as novelty, complexity, uncertainty and conflict (Kashdan et al., 2004).

The second main perspective of curiosity is that provided by conglomerating the works of Hebb, Piaget and Hunt. This view, which is more cognitive in nature, observes that curiosity is evoked by incongruity between something, an event or object, and a person's existing world view (Rowson et al., 2012). Piaget, in particular, viewed curiosity as part of the process of assimilation, an outcome of cognitive disequilibrium. To Piaget, children are curious from birth, with developing cognitive schemas leading to new opportunities for surprising experiences that are discrepant from what a child believes (Jirout \& Klahr, 2012). The incongruity theory of curiosity identified the possibility of two extreme violations of existing expectations. Minor violations of normality are considered too trivial to excite curiosity in the individual, while enormous violations are often difficult for the individual to process resulting in the incongruity being ignored entirely or curiosity being over powered by fear.

George Loewenstein's information gap theory of curiosity tends to gain more traction than the two previous viewpoints. This third model, which consolidates on the gains of the incongruity theory, frames curiosity as the desire to close an information gap between a given reference point (some desired knowledge) and a person's existing information set (Rowson et al., 2012). Loewenstein (1994) posited that curiosity increases the likelihood that the information or experience being sought will close the information gap. This perspective of curiosity provides the framework for the design of engaging instructional strategies for educational purposes. Psychologically, engaged learners are intrinsically motivated by curiosity, interest and enjoyment and are likely to want to achieve their own intellectual or personal goals (Jablon \& Wilkinson, 2006). Litman (2005) observed that Loewenstein's unique emphasis on the magnitude of knowledge gaps as stimulators of curiosity provides a valuable and meaningful reconceptualization of novelty, complexity and ambiguity in terms of cognitive perceptual processes, such as stimulus identification and meta-memory. 
The fourth perspective of curiosity is the most recent and novel view point available in reported literature. Rowson et al. (2012) attributed tactile curiosity to the works of Richard Sennett, and Matthew Crawford. According to the theory of tactile curiosity, curiosity arise from physical engagement with things that are believed might change. The focal point of this approach to curiosity is that working with one's hand can take a person beyond some of the ways the mind can limit their curiosity. The perceptual world is not comprised merely of objects that are passively imbedded, but of affordances that lead one to think and act in certain ways depending on what they mean to them. The idea here is that by thinking with the hands, quite complex suppositions can spring into life and go into quick execution. For the student, this may entail an effort to draft out curious conjectures with the sole aim of pursuing more enriched learning experience.

Curiosity, therefore, is a complex ability, related to several functions of the mind (Perlovsky, Bonnoit-Cabanac \& Cabanac, 2010). Curiosity dictates the deployment of scarce resources in the quest for answers. The cycle of events leading to activities mastery often starts with curiosity, irrespective of the individual's level of education. Science curiosity, being an appetite to seek out and consume information in science related media for personal pleasure has been theorized to impact numeracy, cognitive reflection, science comprehension, and like measures of reasoning proficiency (Kahan et al. 2017). This effect is produced by the recruitment of conscious, effortful information processing to protect the interest that the individuals have in forming beliefs that affirm their identities in chosen fields and disciplines. These identities, particularly within mathematics education, are adjudged indispensable to building strong positive mentality and confidence among mathematics education students, leading to students feeling good, thinking hard and actively participating in their own mathematics learning (Iji, Abah \& Anyor, 2017).

\section{The Connection to Academic Performance}

Generally, most perspectives of curiosity hold that in order for curiosity to be present, the student must already possess some form of knowledge. Identification of manageable knowledge gaps that complement the natural curiosity in a learner, combined with explicit connections to the learner's value system, will often generate tension-to-learn in the learner, (Burns \& Gentry as cited in Borowske, 2005). As such, the engaged learner demonstrates behaviours of concentration, investment, enthusiasm and effort (Jablon \& Wilkinson, 2006). This display of systematic commitment on the part of the learner is a source of science 
curiosity, a vital ingredient of academic performance, particularly for the mathematics education student.

The earliest mention of science curiosity dates back to the phenomenal works of Williams James who in 1890 published The Principles of Psychology. Borowske (2005) reported that James described a scientific curiosity in which the brain responds to an inconsistency or a gap in its knowledge, just as the musical brain responds to a discord in what it hears. Science curiosity has been defined as the heterogeneous disposition to seek out and consume scientific information for personal pleasure (Kahan et al., 2017). Science curiosity could be aroused when individuals feels as though they are deprived of information, and wish to reduce or eliminate their ignorance, as well as when they do not feel particularly deficient of information but would nevertheless enjoy learning something new (Litman, 2005). The feeling of deprivation in the learner is expected to build a persistent thirst for more information, even if for nothing but for the enjoyment derivable from such situation and activation of curiosity.

For the mathematics education students in Nigerian universities, who are perpetually confronted by enormous challenges, sustained curiosity must be cultivated. Often instructional techniques, educational facilities and lecture schedules enforce a reasonable level of constraint on the capacity of the education system to deliver on its goals and objectives. In such learning environments, science curiosity should result in the delighted expectation of discovering something rewarding, entertaining or aesthetically pleasing with respect to academic work of mathematics education students. Such intrinsic curiosity must have deposited a measure of impact on students' academic performance.

In an empirical study from Hong Kong higher education, Hon-Keung, Man-Shan and Lai-Fong (2012) observed that students with curiosity showed higher intrinsic motivation towards acquiring knowledge in certain subjects, resulting in improved performance. Kaufman (2013) also reported a relationship between openness to experience and creative achievement in a study involving 146 English Sixth Form students. Another study of 308 undergraduate college students affirms a relationship between openness and GPA which was mediated by reflective learning styles, suggesting that being intellectually curious fully enhances academic performance (Komarraju, Karau, Schmeck \& Audic, 2011). These and several other studies sufficiently link curiosity to academic performance. 
The present study, however, is unique in its specific identification with science curiosity. This was made possible by the most recent light shed on the construct by Kahan et al. (2017). This current study also drives home the point that education in science technology, engineering and mathematics (STEM) demands essentially similar thought processes which can be aided, to a great extent, by science curiosity. Given the context of the unimaginable information processing power of the present technological era, this study assumes mathematics education students' openness to explore both conventional and social media in fostering their own learning. The study seeks to ascertain the relationship between the science curiosity levels of undergraduates of mathematics education in a Nigerian higher educational institution and their academic grade point averages (GPA). The study further seeks to determine how strong the relationship is, if it exists.

\section{Research Questions}

The following questions were raised to guide this study:

i. What is the relationship between science curiosity and academic performance among mathematics education students?

ii. How is this relationship affected by gender?

\section{Research Hypotheses}

The following hypotheses were tested at 0.05 level of significance

i. There is no significant relationship between science curiosity and academic performance among mathematics education students.

ii. There is no significant difference between the science curiosity levels of male and female mathematics education students.

\section{Methodology}

The study employed a correlation survey research design. The target population is 437 mathematics education students enrolled into the three mathematics education programme options (B. Sc (Ed) mathematics and Computer Science, B. Sc (Ed) Mathematics and Statistics and B. Sc (Ed) Statistics and Computer Science) of a federal University in the North Central region of Nigeria. Simple random sampling was used to select 104 mathematics education students (84 males and 20 females). 
The instrument for data collection in this study was the Science Curiosity Scale Comparative Self-Report (SCS-CSR) originally developed and validated for a study by Kahan, Landrum, Carpenter, Helft and Jamieson (2017). The SCS-CSR has a Cronbach alpha coefficient of 0.80 indicating a high level of internal consistency. The SCS-CSR measures a distinctive appetite for consuming science-related media for personal edification. To maximize social-desirability bias, the SCS-CSR camouflaged items relating to science interest by seeding them in large blocks of "personal interest" items relating to sports, finance, politics, popular entertainment and other issues (Kahan et al. 2017). For this particular study, the respondents were told the instrument was for a general survey, thereby masking the true intention of the questionnaires.

This deployment of the science curiosity scale was carefully handled to take care of the special needs of a Nigerian respondent, as such, items such as the leisure activity of "attending a gun show" was replaced with "visiting a tech hub". Also, to reflect the interconnectivity of STEM fields as represented in the nomenclature of the mathematics education degree programmes of the subjects in this study, the terms "technology" "engineering" and "mathematics" were added to every specific reference to "science" and "scientific research discoveries". The selection of the measures of science curiosity on the SCS-CSR was done with respect to items relating to STEM and general education. For instance, in section 2 (Leisure Activity), items of interest to this research include visiting a science museum, tech hub, zoo or aquarium and public library (outside school).

It is also important to emphasize that the university students who were the subjects surveyed for this research have access to these extra-curricular activities that are reflected on the SCS-CSR Instrument. Although Nigeria has faced some challenges in the provision of these science-based facilities/activities, they are not absent. Some zoos and botanical gardens within the study area continue to function, though, they might not be as rich as those in richer countries, and science conferences, talk shows and expositions are constantly been held. Global technology penetration reports also indicate high levels of smartphone adoption among Nigerian students (World Bank, 2016; Twinpine Network, 2017; Nigerian Communications Commission, 2018). All of this supports the suitability of the social media - based sections of the Instrument for a sample of Nigerian undergraduates.

It is important to note that while the original study by Kahan et al. (2017) administered the science curiosity scale online; this deployment is a paper-based administration. Scoring of 
Likert-style sections conforms to the original scale, but items on number of times a respondent engaged in a leisure activity and checking of book topics were scored 1 for participating (even for just once) and 0 for not participating. In summary, the SCS-CSR yields a total of 17 items of interest with a highest obtainable score of 44 and a lowest obtainable score of 9.

The students used for this study all gave their consent to participate in the survey and freely indicated their registration (identification) number on the questionnaire strictly for the purpose of aiding efficient correlation to their grade point averages (GPA). The GPAs were obtained from the most current available examination records at the department hosting the three undergraduate options.

Pearson Product Moment Correlation Coefficient (PPMCC) was computed to answer the research questions. Firstly, students' science curiosity scores were correlated to their grade Point Averages (GPAs) obtained from students' examination records for second semester of the 2014/2015 academic session to answer the fist research question. Secondly, the students were grouped according to gender (male and female) and their science curiosity scores correlated to their GPAs. The correlation coefficients from the two groups are then compared.

The first hypothesis was tested using paired t-test of significance. The second hypothesis was tested using unpaired t-test. Both hypotheses were tested at 0.05 level of significance

\section{Results and Discussion}

The results of this study are presented with concurrence to the research questions and hypotheses.

\section{Research question one:}

What is the relationship between science curiosity and academic performance among mathematics education students? 
Table 1:

Pearson Correlation between Science Curiosity and Academic Performance

\begin{tabular}{lll}
\hline Variable & N & $\begin{array}{l}\text { Correlation } \\
\text { Coefficient (r) }\end{array}$ \\
\hline Science curiosity & 104 & -0.049 \\
Academic performance & 104 & \\
\hline
\end{tabular}

The results in Table 1 indicate a Pearson Product Moment Correlation Coefficient of 0.049, implying a weak negative relationship between science curiosity and academic performance among mathematics education students.

Research question two:

How is this relationship affected by gender?

Table 2:

Pearson Correlation between Science curiosity and Academic performance of Male mathematics Education students

\begin{tabular}{lcl}
\hline Variable & N & $\begin{array}{l}\text { Correlation } \\
\text { Coefficient (r) }\end{array}$ \\
\hline Science curiosity & 84 & -0.060 \\
Academic performance & 84 & \\
\hline
\end{tabular}

The result in Table 2 indicates a weak negative relationship between science curiosity and academic performance among male mathematics education students.

Table 3:

Pearson Correlation between Science Curiosity and Academic Performance of Female Mathematics Education Students

\begin{tabular}{lll}
\hline Variable & N & $\begin{array}{l}\text { Correlation } \\
\text { Coefficient (r) }\end{array}$ \\
\hline Science curiosity & 20 & -0.002 \\
Academic performance & 20 & \\
\hline
\end{tabular}


The result in Table 3 indicates a weak negative relationship between science curiosity and academic performance among female mathematics education students.

The values for the Pearson Product Moment Correlation Coefficient displayed in Tables 2 and 3 indicate that though there is a weak negative relationship between science curiosity and academic performance among both gender, the relationship is stronger for the male mathematics education students than for the female mathematics education students. This implies that the male gender seems to display a more appreciable connection between science curiosity and academic performance.

Research hypothesis one:

There is no significant relationship between science curiosity and academic performance among mathematics education students.

\section{Table 4:}

Test of Significance of Correlation between Science Curiosity and Academic Performance

\begin{tabular}{llll}
\hline Variable & $\mathbf{N}$ & $\begin{array}{l}\text { Correlation } \\
\text { Coefficient (r) }\end{array}$ & p-value \\
\hline Science curiosity & 104 & & 0.6210 \\
Academic performance & 104 & -0.049 & \\
\hline$\alpha=0.05$ & & &
\end{tabular}

The result in Table 4 indicates that the p-value of 0.6210 is greater than the significance level of 0.05 , implying that the correlation is not significant. Glaringly, there is no sufficient evidence from relationship between science curiosity and academic performance observed among the sampled mathematics education students to reject the stated hypothesis.

\section{Research hypothesis two:}

There is no significant difference between the science curiosity levels of male and female mathematics education students 
Table 5:

Unpaired t-test of Science Curiosity Scores of Male and Female Mathematics Education Students

\begin{tabular}{lllllll}
\hline Gender & N & Mean & $\begin{array}{l}\text { Standard } \\
\text { Deviation }\end{array}$ & $\begin{array}{l}\text { t- } \\
\text { calculated }\end{array}$ & t-critical & p-value \\
\hline Male & 84 & 28.274 & 6.645 & 0.257 & 1.983 & 0.7976 \\
Female & 20 & 28.700 & 6.729 & & & \\
\hline
\end{tabular}

$$
\alpha=0.05
$$

The result of the unpaired t-test shown in Table 5 indicates that the means are not significantly different considering the p-value of 0.7976 which is greater than the stated level of significance (0.05). This implies that the null hypothesis cannot be rejected based on the available data in this study.

All the results emanating from the data analysis in this study are surprisingly unique when viewed along existing trends of similar researches. From Table 1, it was established that there is a weak negative relationship between science curiosity and academic performance of mathematics education students from Nigerian higher education. This finding is particularly in sharp contrast with Komarraju, Karaa, Schmeck and Avdic (2011) who suggested that being intellectually curious fully enhances academic performance. The fact that the observed weak negative relationship was statistically not significant (as shown in Table 4) points to the dynamics of the sample of mathematics education students used in this study. Thus, it is possible that other important factors which are outside science curiosity could be at play with respect to the academic performance of the students. Such underlying factors could be attributed to individual students' inputs in terms of effort, ability, and personal engagement (Cybinsky \& Forster, 2009), and which could not be differentiated by the instrument of this study. This eventuality may have highlighted the need to reconsider university students' unique experiences, personal competencies, natural support systems and individual definitions as inherent drivers of overall progress, particularly in higher education (Abah, 2017; Williams, 2011). This outcome is in line with observations by Kahan et al. (2017) that one would expect a science-curiosity measure, if valid, to be modestly correlated with, but definitely not equivalent to, a valid science-comprehension or achievement measure. 
However, the non-significant correlation established between science curiosity and academic achievement in this study may not be so surprising if this finding is considered in the light of the mixed-method study by Smith (2010) whose findings showed no significant relationship between curiosity and academic achievements of design students in a studio setting. Furthermore, Smith (2010) found no significant difference in curiosity levels between male and female design students.

In terms of gender, male mathematics education students were found to display stronger relationship between science curiosity and academic performance (Tables 2 and 3 ) than their female counterparts, even though this relationship is in the negative region. However, it was established in Table 5 that there is no significant difference between the science curiosity levels of male and female mathematics education students. This disagrees with the cross-cultural study which reported higher levels of curiosity among male Israeli college students (Ben-Zur \& Zeidner, 1988) and Gutten, Yaman, Deringol and Ozsari (2011) who found that female students' curiosity level was statistically higher than male students.

\section{Conclusion}

This study set out to investigate the relationship between science curiosity and academic performance of mathematics education students in Nigeria. A key premise of this study is the idea that the cycle of events leading to activity mastery as measured by students' cumulative grade point averages often start with curiosity, irrespective of the stage of education. The perspectives of literature on curiosity were considered along with reported connections to academic performance. Analysis of the data obtained from the study revealed a weak negative correlation of science curiosity to academic performance for the mathematics education students used in this study. This outcome points to the possibility of other concomitant factors acting as principal drivers of academic proficiency in Nigerian higher education, making it difficult to make generalization based on science curiosity alone.

\section{Recommendations}

Based on the findings of this study, the following recommendations are put forward:

i. Key stakeholders of mathematics education should always underscore the complexity of curiosity in every attempt to properly deploy scarce resources in the quest for all round development of the learner. 
Science Curiosity as a Correlate of Academic Performance in Mathematics Education: Insights from Nigerian Higher Education

ii. Mathematics education students should always strive to make adequate use of modern technology to drive more personalized learning.

iii. Mathematics education students should eagerly make use of available science facilities such as Museums, Science fairs, and Science-based symposiums/and conferences within and outside their campuses to enrich their overall journey as students.

iv. Universities and colleges of education should innovate avenues for stirring up students' science curiosity through provision of exciting science-based extracurricular activities such as science fairs, science-based quiz competitions and educative debates on the processes and products of science.

\section{Suggestions for Further Study}

Considering the outcome of this attempt in investigating the linear correlation between science curiosity and academic performance, future studies could expand the scope of the present work to incorporate other related variables. Could the technology dependent approach to measuring science curiosity have unveiled existing dispositional inattentiveness among students? These and other prospective perspectives could form the basis of further investigations.

\section{References}

Abah, J. A. (2017). Original higher education experience of graduating students of mathematics education in Nigeria: An autoethnographic approach. Education Journal, 6(6), 177187. doi: 10.11648/j.edu.20170606.13 . A publication of Science Publishing Group, USA. Retrieved on $1^{\text {st }} \quad$ February, 2018 from http://article.sciencepublishinggroup.com/pdf/10.11648.j.edu.20170606.13.pdf

Arnone, M.P., Small, R.V., Chauncey, S.A. \& McKenna, H.P. (2011). Curiosity, interest and engagement in technology pervasive learning environments: A new research agenda. Education Technology Research Development, 59, 181-198. DOI: 10.1007/s11423011-9190-9

Ben-Zur, H. \& Zeidner, M. (1988). Sex differences in anxiety, curiosity and anger: A crosscultural study. Sex Roles, 19(5), pp 335-347. DOI:10.1007/BF00289841

Borowske, K. (2005). Curiosity and motivation-to-learn. Communicacion presentada a la ACRL Twelfth National Conference, 346-350. 
Cybinsky, P.J. \& Forster, J. (2009). Student preparedness, effort and academic performance in quantitative business course. In D.T. Nguyen (Ed.) Discussion Papers Economics. Brisbane: Griffith Business School. Pp 1-35

Gulten; D.G, Y., Deringol, Y., \& Ozsari, I. (2011). Investigating the relationship between curiosity level and computer self-efficacy beliefs of elementary teachers. Turkish Online Journal of Educational Technology, 10 (4), 248-254.

Hon-Keung, Y., Man-Shan, K. \& Lai-Fong, C.A. (2012). The impact of curiosity and external redulation on intrinsic motivation: An empirical study in Hong Kong education. Psychology Research, 2(5), 295-307.

Iji, C.O., Abah, J.A. \& Anyor, J.W. (2017). Impact of cloud services on students' attitude towards mathematics education in public universities in Benue State, Nigeria. International Journal of Research in Education and Science (IJRES), 3(1), 228-244. A publication of the International Society for Research in Education and Science (ISRES). $\begin{array}{lllll}\text { Retrieved } & \text { on } & 1^{\text {st }} & \text { February, } & 2018\end{array}$ http://dergipark.ulakbim.gov.tr/ijres/article/download/5000202010/5000179858

Jablon, J.R. \& Wilkinson, M. (2006). Using engagement strategies to facilitate children's learning and success. Beyond the Journal - Young Children on the Web, March 2016, $1-5$.

Jirout, J. \& Klahr, D. (2012). Children's scientific curiosity: In search of an operational definition of an elusive concept. Developmental Review, 32(2), 125-160.

Kahan, D.M., Landrum, A.R., Carpenter, K., Helft, L. \& Jamieson, K.H. (2017). Science curiosity and political information processing. Advances in Political Psychology, 38(Suppl. 1). doi: 10.1111/pops.12396. Retrieved on $1^{\text {st }}$ February, 2018 from http://onlinelibrary.wiley.com/doi/10.1111/pops.12396/full

Kashdan, T.B., Rose, P. \& Fincham, F.D. (2004). Curiosity and exploration: Facilitating positive subjective experiences and personal growth opportunities. Journal of Personality Assessment, 82(3), 291-305.

Kaufman, S.B. (2013). Opening up openness to experience: A four-factor model and relations to creative achievement in the arts and sciences. The Journal of Creative Behaviour, 47(4), 233-235. 
Science Curiosity as a Correlate of Academic Performance in Mathematics Education: Insights from Nigerian Higher Education

Komarraju, M., Karau, S.J., Schmeck, R.R. \& Avdic, A. (2011). The big five personality traits, learning styles, and academic achievement. Personality and Individual Difference, 51, 472-477.

Litman, J.A. (2005). Curiosity and the pleasures of learning: Wanting and liking new information. Cognition and emotion, 19(6), 793-814.

Loewenstein, G. (1994). The psychology of curiosity: A review and reinterpretation. Psychological Bulletin, 116(1), 75-98.

McGillivary, S., Murayama, K. \& Castel, A.D. (2015). Thirst for knowledge: The effects of curiosity and interest on memory in younger and older adults. Psychology and Aging, $30(4), 835-841$.

Nigerian Communications Commission (2018). Subscriber statistics. Retrieved on 2nd February, 2018 from https://ncc.gov.ng/13-stakeholder-information/statistics-reports

Perlovsky, L., Bonniot-Cabanac, M.C. \& Cabanac, M. (2010). Curiosity and pleasure. Neurons and Cognition, The 2010 International Conference on Neural Networks. DOI:10.1109/IJCNN.2010.5596867

Rowson, J., Young, J., Spencer, N., Lindley, E. \& Gecius, E. (2012). The power of curiosity: How linking inquisitiveness to innovation could help to address our energy challenges. London: RSA Social Brain Centre. p 1-37.

Smith, K.H. (2010). Curiosity and pedagogy: A mixed methods study of student experiences in the design studies. Ed. D. Dissertation submitted at the University of Arkansas. Pro Quest Dissertations Publishing. pp 1-50.

Steinmayr, R., Meibner, A., Weidinger, A.F. \& Wirthwein, L. (2015). Academic achievement. $\begin{array}{llll}\text { Retrieved } & \text { on } & 10^{\text {th }} & \text { September, }\end{array}$ http://www.oxfordbibliographies.com/view/document/obo-9780199756810/obo9780199756810-0108.xml

The Royal Society (2010). The scientific century: Securing our future prosperity. London: The Royal Society. pp 8-72. 
Twinpine Network (2017). 2016 Nigeria mobile trends report. Retrieved on 2nd February, 2018 from http://twinpinenetwork.com/report/

Von Stumm, S., Hell, B. \& Chamorro-Premuzic, T. (2011). The hungry mind - Intellectual curiosity is the third pillar of academic performance. Perspectives on Psychological Science, 6(6), 574-588.

Williams, E. (n.d.). What is the meaning of academic performance? Retrieved on $10^{\text {th }}$ September, 2016 from http://work.chron.com/meaning-academic-performance$\underline{17332 . h t m l}$

Williams, J.M. (2011). Home, school, and community factors that contribute to the educational resilence of urban African American high school graduates from low-income, singleparent families. $\mathrm{PhD}$ (Doctor of Philosophy) thesis. Retrieved on $20^{\text {th }}$ February, 2017 from http://ir.uiowa.edu/etd/1191

World Bank (2016). World Development Report 2016: Digital Dividends. Washington, DC: World Bank. doi: 10.1596/978-1-4648-0671-1 